\title{
Histopathological and microbiological study of porcine lymphadenitis: contributions to diagnosis and control of the disease
}

\author{
Fernando Cardoso-Toset ${ }^{1}$, Jaime Gómez-Laguna², Lidia Gómez-Gascón ${ }^{3}$, Irene M. Rodríguez-Gómez²,
} Angela Galán-Relaño ${ }^{3}$, Librado Carrasco ${ }^{2}$, Carmen Tarradas ${ }^{3}$, Ana I. Vela ${ }^{4,5}$ and Inmaculada Luque ${ }^{3^{*}}$ (i)

\begin{abstract}
Tuberculosis like lesions (TBL) in free-range pigs are characterised by presenting a marked heterogeneity in pathology and microbiology features, with a notorious role of Mycobacterium tuberculosis complex (MTC), Trueperella pyogenes and different Streptococcus species. However, the capacity of these microorganism to spread to different organic cavities leading to a generalised disease is unknown. Therefore, this study evaluated the organic distribution of these agents in free-range pig carcasses whole condemned due to generalised TBL. A total of 37 totally condemned animals were analysed, and samples of lymph nodes and organs were obtained $(n=262)$ and subjected to histopathological and microbiological examination. In addition, T. pyogenes and streptococci species were further characterised by PFGE analysis. Two different patterns were evidenced with lack or occasional lesions in superficial inguinal (SILN) and popliteal (PLN) lymph nodes and advanced lesions in submandibular (SLN) (35/36) and gastrohepatic (GHLN) (33/35) lymph nodes (stages III and IV). Early stage granulomas (stage I and II) prevailed in lungs (16/20), liver (14/31) and spleen (7/18). The microbiological analysis revealed that MTC, detected by GPCR, was present in 31 out of 37 animals and 90 (90/262) samples. In 26 out of the 31 pigs, MTC was detected from two or more organs. SLN (24/31) and GHLN (19/31) were the MTC ${ }^{+}$organs most frequently detected, with 29 out of $31 \mathrm{MTC}^{+}$pigs detected as positive in one or both samples, which points out that both lymph nodes must be included in the sampling of surveillance programs. Other pathogens, such as $T$. pyogenes and Streptococcus spp., were also involved in generalised lymphadenitis, being frequently isolated from SLN and other organs, such as liver (T. pyogenes), tonsils or lung (Streptococcus spp.). A wide genetic diversity among streptococci was observed, showing the ubiquitous character of these pathogens, however, the isolation of a single clone of $T$. pyogenes from different organic locations from animals with generalised TBL was a common finding of this study, highlighting that the role of this pathogen in porcine lymphadenitis may be underestimated. These results should be considered in future studies on the pathogenesis and control of porcine lymphadenitis.
\end{abstract}

Keywords: Free-range pigs, Lymphadenitis, Tuberculosis like lesions, Mycobacterium tuberculosis complex, Trueperella pyogenes, Streptococcus spp.

\footnotetext{
* Correspondence: sa1lumoi@uco.es

${ }^{3}$ Department of Animal Health, University of Córdoba, International Excellence Agrifood Campus 'CeiA3', 14071 Córdoba, Spain

Full list of author information is available at the end of the article
}

C C The Author(s). 2020 Open Access This article is licensed under a Creative Commons Attribution 4.0 International License, which permits use, sharing, adaptation, distribution and reproduction in any medium or format, as long as you give appropriate credit to the original author(s) and the source, provide a link to the Creative Commons licence, and indicate if changes were made. The images or other third party material in this article are included in the article's Creative Commons. licence, unless indicated otherwise in a credit line to the material. If material is not included in the article's Creative Commons licence and your intended use is not permitted by statutory regulation or exceeds the permitted use, you will need to obtain permission directly from the copyright holder. To view a copy of this licence, visit http://creativecommons.org/licenses/by/4.0/. The Creative Commons Public Domain Dedication waiver (http://creativecommons.org/publicdomain/zero/1.0/) applies to the data made available in this article, unless otherwise stated in a credit line to the data. 


\section{Background}

Porcine lymphadenitis is commonly an asymptomatic disease that involves the inflammation of superficial and deep lymph nodes in response to infection by different microorganisms, which can spread to other organs, mainly lungs, liver and spleen $[15,17]$. Macroscopically, these lesions are characterised by their nodular appearance, which may be caseous, purulent or proliferative [4, 10] and are frequently listed in the literature as tuberculosis-like lesions (TBL). TBL are most detected during postmortem inspection and result in partial or whole carcass condemnation at the slaughterhouse with a relevant economic impact for producers [15].

TBL are characterised by presenting a marked heterogeneity in pathology, microbiology, and immunological features both in humans and animals $[5,7,12]$. In this sense, not only different lesional patterns may be identified by histopathology but also a wide range of microorganisms can be detected, with mycobacteria belonging to Mycobacterium avium complex (MAC), Mycobacterium tuberculosis complex (MTC) and Rhodococcus equi as the species most frequently associated with TBL in domestic and feral pigs $[2,8,16,17,21,24,25]$. However, the complex aetiology and wide spectrum of microorganisms different to mycobacteria that can be involved in TBL in free-range pigs have been recently evidenced, with Trueperella pyogenes and several Streptococcus species underscored as the main non-tuberculous microorganisms associated with these lesions [7].

According to the chronic course of this disease, the identification of the causative agents can be a complicated task, especially when several pathogens or different isolates of the same species may be involved. These facts may be important in establishing the diagnostic methods and the control measures [5, 7 , 17]. The characteristics and distribution of the lesions and bacteria identified provide valuable information on the mechanisms of transmission and the role played by the pig in the maintenance and dissemination of diseases of importance to both animal and public health [23, 29]. This information will allow gaining knowledge of interest to understand the pathogenesis of TBL in pigs as well as identifying target organs for the diagnosis of the main pathogens involved in this process to avoid misdiagnosis and the implementation of holistic control measures. Therefore, the organic distribution of MTC, T. pyogenes and Streptococcus species involved in TBL from whole condemned free-ranged pig carcasses due to generalised lymphadenitis was evaluated in this study. In a second step, non-tuberculous microorganisms were further characterised to determine the genetic similarity among isolates obtained from different organs from the same carcass with generalised disease.

\section{Results}

\section{Histopathological analysis}

A total of 206 samples belonging to 37 animals were subjected to the histopathological examination. Since samples needed to be split into two portions, all samples were not always available to perform all the studies.

Two different lesional patterns were evidenced in lymph nodes with lack or occasional lesions observed in SILN and PLN and prominent and advanced lesions detected in SLN and GHLN. Therefore, only 1 out of 18 SILN and 4 out of 34 PLN presented granulomatous inflammation consisting of a combination of granulomas of different stages. Late stage granulomas (stages III and IV) were overrepresented in SLN and GHLN (35/36 and $33 / 35$ samples, respectively), which were commonly found in combination with satellite pyogranulomas and granulomas of earlier stages (stages I and II) (Fig. 1). Numerous multicentric granulomas with several mineralisation foci as well as extensive necrosis were frequent (Fig. 2). Stage IV granulomas was the only lesion found in three SLNs and two GHLNs. No microscopic lesions were observed in 1/36 SLN and 2/35 GHLN.

Early stage granulomas (stage I and II) were the predominant lesions observed in lungs (16/20) (Fig. 3), liver $(14 / 31)$ (Fig. 4) and spleen (7/18), which were usually detected in combination with pyogranulomas and granulomas of later stages (stage III and IV granulomas, but usually with only one or two multicentric granulomas). Numerous pyogranulomas were uniquely found in the lung of one animal. No microscopic lesions were observed in 1/20 lung, 9/31 liver and 7/18 spleen samples, despite they were grossly evidenced (data not shown).

\section{TB diagnosis}

MTC was detected $\left(\mathrm{MTC}^{+}\right)$in $31(83.78 \%)$ out of 37 animals and $90(34.35 \%)$ out of 262 samples, respectively (Table 1). Considering the organic location, SLN (24/31; $77.42 \%)$ and GHLN (19/31; 61.29\%) were the organs where MTC was most frequently detected by qPCR, with 29 (93.55\%) out of $31 \mathrm{MTC}^{+}$animals yielding a positive result in at least one of these lymph nodes.

MTC was also detected from spleen (9/31), SILN $(11 / 31)$, lungs $(8 / 31)$, liver $(8 / 31)$ and tonsils $(4 / 31)$ from $\mathrm{MTC}^{+}$animals (Table 1). MAC was only detected in one pig with TBL in the liver. In 26 (83.87\%) out of the 31 $\mathrm{MTC}^{+}$animals this pathogen was detected in two or more organic locations.

A predominance of mineralised lesions (stage IV granulomas) were observed in lymph nodes of the six MTC negative $\left(\mathrm{MTC}^{-}\right)$animals. However, in 4 out of these $6 \mathrm{MTC}^{-}$animals early stage granulomas (stage I and stage II granulomas) were also observed either in lymph nodes or in the other examined organs, such as lungs, liver or spleen. 


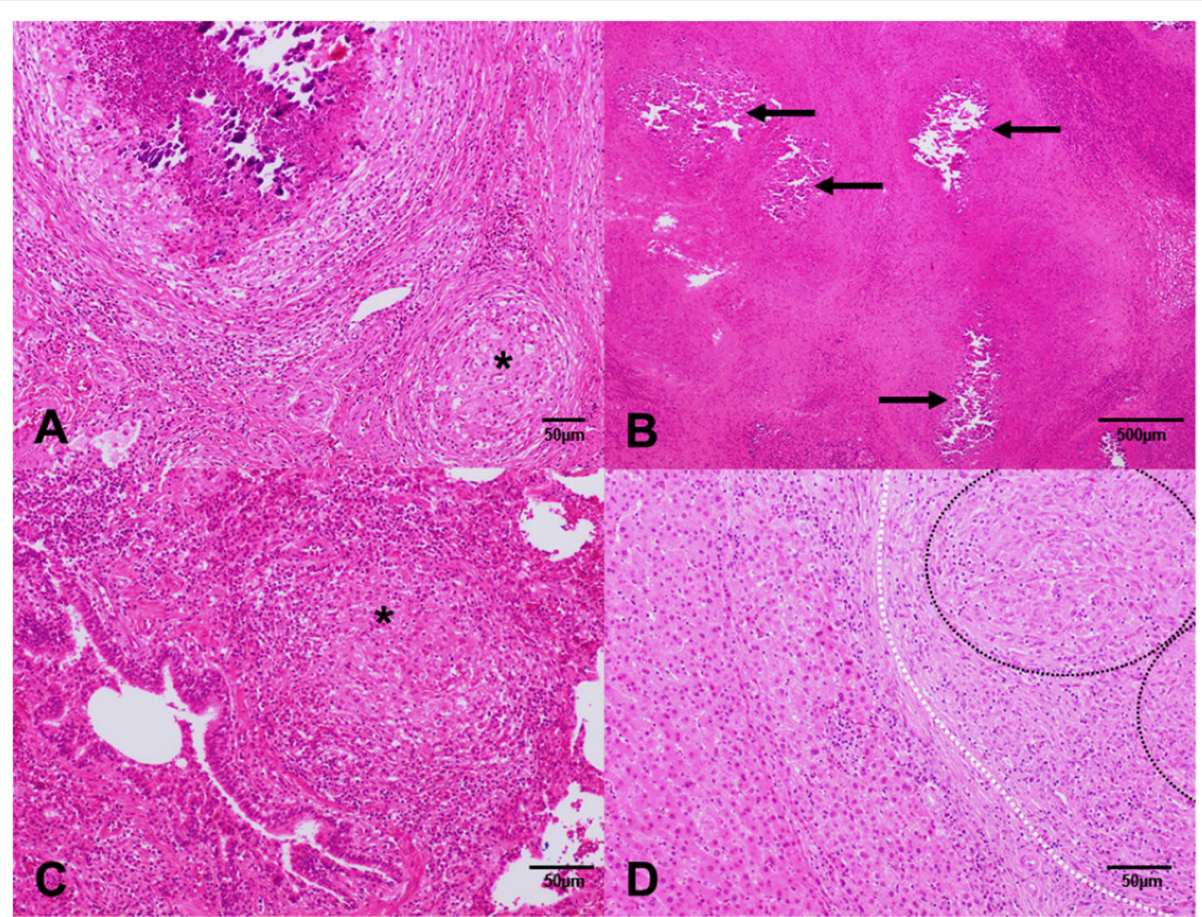

Fig. 1 Granuloma stages (I-IV) in tissues from pigs. a Granuloma, submandibular lymph node, pig. Stage IV granuloma with a thick connective tissue capsule, and a prominent caseous necrotic core with multifocal islands of mineralization, accompanied by a satellite stage II granuloma (asterisk), composed by epithelioid macrophages enclosed by a thin capsule, with peripheral infiltration of scattered lymphocytes. Hematoxylin and eosin (HE). Bar, 50 m. b Granuloma, submandibular lymph node, pig. Multicentric granulomas with several mineralization foci (arrows) as well as extensive necrosis. HE. Bar, 500 mm. c Granuloma, lung, pig. Clustered epithelioid macrophages surrounded by lymphocytes and erythrocytes in a stage I granuloma in the lung. HE. Bar, 50 um. d Granuloma, liver, pig. Coalescent stage II granulomas (dashed black circles) showing epithelioid macrophages enclosed by a thin connective tissue capsule (dashed white line), with mild peripheral infiltration of scattered lymphocytes. HE. Bar, $50 \mu \mathrm{m}$

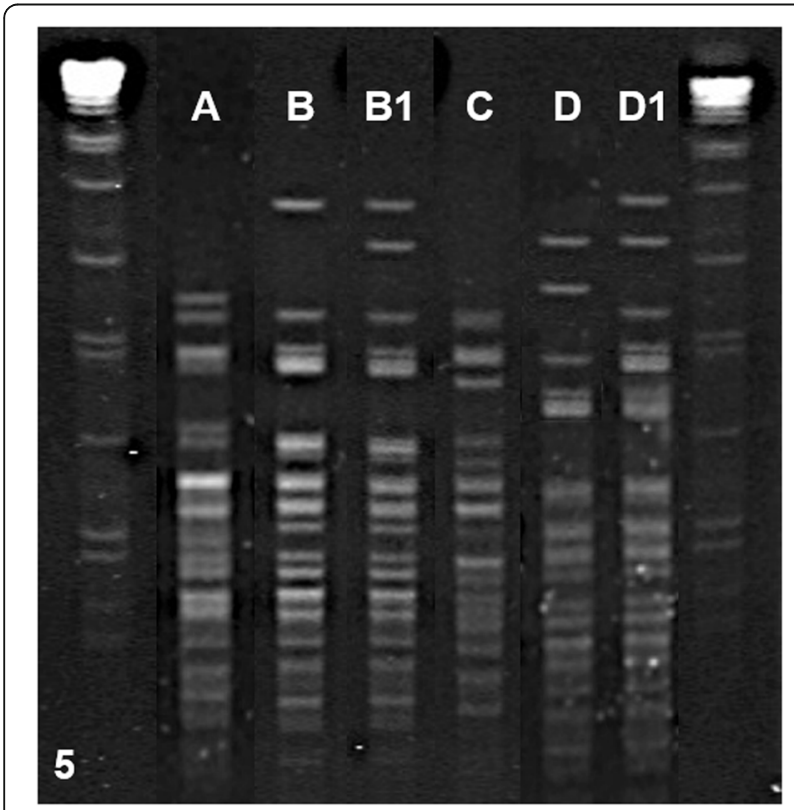

Fig. 2 Molecular characterisation of Trueperella pyogenes isolates by PFGE, using the restriction enzyme Bcul. A pattern of 15 to 18 well differentiated bands in the gel were obtained, grouping the isolates in 6 different pulsotypes (A, B, B1, C, D and D1)

\section{Bacterial isolation}

A total of 152 isolates were obtained (Table 1) with $T$. pyogenes, S. porcinus and S. dysgalactiae spp. equisimilis as the most frequently non-tuberculous microorganisms detected from animals (43.24, 40.54, 37.84\%, respectively) and analysed samples (26.31, 18.42, 16.45\%, respectively). A wide tissue distribution was observed for these microorganisms, with emphasis mainly on $T$. pyogenes isolation from the liver $(8 / 34 ; 23.53 \%)$, SLN $(7 / 37 ; 18.92 \%)$ and SILN (7/36; 19.44\%); S. porcinus detection in tonsils (9/21; $42.86 \%)$, lungs $(5 / 37 ; 13.51 \%)$ and SLN $(4 / 37 ; 10.81 \%)$; and S. dysgalactiae spp. equisimilis in SLN $(5 / 37 ; 13.51 \%)$ and lungs $(5 / 37 ; 13.51 \%)$. Other bacteria isolated with lower frequency are showed in Table 1.

Regarding bacterial dissemination, $T$. pyogenes was isolated from two or more organs in 8/16 (50.0\%) animals, S. porcinus in $5 / 15(33.33 \%)$ and S. dysgalactiae spp. equisimilis in $6 / 14(42.86 \%)$ animals, respectively (Table 2). These isolates were further analysed by PFGE analysis.

\section{PFGE analysis}

Thirty-two T. pyogenes isolates belonging to eight animals with systemic dissemination of the bacterium were 
Table 1 Organic distribution of isolated microorganisms in 37 pigs with generalised TBL

\begin{tabular}{|c|c|c|c|c|c|c|c|c|c|c|}
\hline \multirow[t]{2}{*}{ Microorganisms } & \multirow{2}{*}{$\begin{array}{l}\text { Positive } \\
\text { animals }\end{array}$} & \multirow{2}{*}{$\begin{array}{l}\text { Positive } \\
\text { samples }\end{array}$} & \multicolumn{8}{|c|}{ Organic distribution of detected microorganisms* } \\
\hline & & & SLN & PLN & SILN & GHLN & Lungs & Liver & Spleen & Tonsils \\
\hline MTC & $31(83.78)$ & $90(34.35)$ & $24(64.86)$ & $7(19.44)$ & $11(30.55)$ & $19(52.78)$ & $8(21.62)$ & $8(23.53)$ & $9(37.50)$ & $4(19.05)$ \\
\hline T. pyogenes & $16(43.24)$ & $40(26.31)$ & $7(18.92)$ & $5(13.89)$ & $7(19.44)$ & $3(8.33)$ & $5(13.51)$ & $8(23.53)$ & $3(12.5)$ & $2(9.52)$ \\
\hline S. porcinus & $15(40.54)$ & $28(18.42)$ & $4(10.81)$ & $0(0)$ & $3(8.33)$ & $2(5.55)$ & $5(13.51)$ & $2(5.88)$ & $3(12.5)$ & $9(42.86)$ \\
\hline S. dysgalactiae spp equisimilis & $14(37.84)$ & $25(16.45)$ & $5(13.51)$ & $0(0)$ & $4(11.11)$ & $4(11.11)$ & $5(13.51)$ & $3(8.82)$ & $2(8.33)$ & $2(9.52)$ \\
\hline S. suis & $8(18.92)$ & $8(4.60)$ & $1(2.70)$ & $0(0)$ & $1(2.78)$ & $1(2.78)$ & $2(5.55)$ & $0(0)$ & $0(0)$ & $2(9.52)$ \\
\hline Aerococcus spp $p^{\mathrm{a}}$ & $7(18.92)$ & $9(5.92)$ & $1(2.70)$ & $2(5.55)$ & $3(8.33)$ & $1(2.78)$ & $0(0)$ & $0(0)$ & $0(0)$ & $2(9.52)$ \\
\hline Corynebacterium spp $p^{\mathrm{b}}$ & $4(10.81)$ & $9(5.92)$ & $2(5.40)$ & $2(5.55)$ & $1(2.78)$ & $0(0)$ & $2(5.55)$ & $2(5.88)$ & $0(0)$ & $0(0)$ \\
\hline S. equi zooepidemicus & $4(10.81)$ & $6(3.95)$ & $0(0)$ & $0(0)$ & $0(0)$ & $2(5.55)$ & $1(2.70)$ & $0(0)$ & $1(4.17)$ & $2(9.52)$ \\
\hline S. dysgalactiae spp. dysgalactiae & $2(5.40)$ & $4(2.63)$ & $1(2.70)$ & $0(0)$ & $2(5.55)$ & $0(0)$ & $1(2.70)$ & $0(0)$ & $0(0)$ & $0(0)$ \\
\hline S. agalactiae & $3(8.11)$ & $3(1.97)$ & $1(2.70)$ & $0(0)$ & $0(0)$ & $0(0)$ & $0(0)$ & $1(2.94)$ & $0(0)$ & $1(4.76)$ \\
\hline Rhodococcus equi & $1(2.70)$ & $3(1.97)$ & $1(2.70)$ & $0(0)$ & $0(0)$ & $0(0)$ & $1(2.70)$ & $1(2.94)$ & $0(0)$ & $0(0)$ \\
\hline Globicatella sanguinis & $1(2.70)$ & $3(1.97)$ & $0(0)$ & $0(0)$ & $0(0)$ & $0(0)$ & $1(2.70)$ & $1(2.94)$ & $1(4.17)$ & $0(0)$ \\
\hline S. mitis & $3(8.11)$ & $3(1.97)$ & $0(0)$ & $2(5.55)$ & $0(0)$ & $0(0)$ & $0(0)$ & $1(2.94)$ & $0(0)$ & $0(0)$ \\
\hline S. equinus & $2(5.40)$ & $2(1.31)$ & $1(2.70)$ & $0(0)$ & $0(0)$ & $0(0)$ & $0(0)$ & $0(0)$ & $1(4.17)$ & $0(0)$ \\
\hline Streptococcus bovis & $2(5.40)$ & $2(1.31)$ & $2(5.40)$ & $0(0)$ & $0(0)$ & $0(0)$ & $0(0)$ & $0(0)$ & $0(0)$ & $0(0)$ \\
\hline Other streptococci ${ }^{\mathrm{C}}$ & $5(13.51)$ & $5(3.29)$ & $0(0)$ & $2(5.55)$ & $0(0)$ & $1(2.78)$ & $1(2.70)$ & $1(2.94)$ & $0(0)$ & $0(0)$ \\
\hline Other microorganisms ${ }^{d}$ & $4(8.11)$ & $3(1.97)$ & $3(8.11)$ & $0(0)$ & $0(0)$ & $0(0)$ & $0(0)$ & $1(2.94)$ & $0(0)$ & $0(0)$ \\
\hline TOTAL & 37 (100) & $262(100)$ & 37 & 36 & 36 & 36 & 37 & 34 & 24 & 21 \\
\hline
\end{tabular}

*SLN, PLN, SILN and GHLN: submandibular, popliteal, superficial inguinal and gastrohepatic lymph nodes, respectively

${ }^{\mathrm{a}} \mathrm{A}$. viridans ( 8 isolates, 6 positive animals), A.urinae ( 1 isolate)

${ }^{\mathrm{b}}$ C. striatum/amynocolatum (6 isolates, 2 positive animals), C. urealitycum (3 isolates, 2 positive animals)

'S. uberis, S. salivarius, S. oralis (1 isolate each), Streptococcus spp. (2 isolates, 2 positive animals)

dMycobacterium avium complex, Cellulomonas/Microbacterium, Lactococcus lactis and Erysipelothrix rhusiopatiae (1 isolate each)

selected to be further characterised by PFGE. Four different PFPs (A, B-B1, C, D-D1) were identified at an $85 \%$ of genetic similarity after $B c u$ I DNA $(4 / 32$, GD 0.13 ) digestion (Table 2, Fig. 5). In 5 animals (5/8; 62.5\%) all isolates displayed an undistinguishable PFGE macrocrestriction pattern with $B c u$ I restriction enzyme. Only one or two different PFPs of this microorganism were obtained from the same animal (Table 2).

However, a wide diversity of PFPs was obtained from animals with organic dissemination of Streptococcus species. The PFGE analysis of $18 \mathrm{~S}$. porcinus isolates obtained from 5 animals showed nine different PFPs (9/ 18; GD 0.5) (Table 2). Undistinguishable PFPs were only detected in one pig $(1 / 5 ; 20 \%)$ (Table 2). The 17 S. dysgalactiae spp. equisimilis isolates recovered from 6 animals displayed eight different PFGE patterns $(8 / 17$, GD 47.06) with two animals showing the same clone in all organs $(2 / 6 ; 33.34 \%)$ (Table 2).

Although our experimental design was not set up to analyse the diversity of the recovered isolates between different farms and the sample size was limited, the PFGE analysis showed some information of interest. Thus, isolates with high genetic similitude of $T$. pyogenes were detected from animals belonging either to the same farm or to different swine herds (farms 5, 6, 7 and 12).
However, a high genetic heterogeneity was observed within the isolates of S. porcinus and S. dysgalactiae spp. equisimilis, with genetically different isolates circulating intra-herd and inter-herds (Table 2).

\section{Discussion}

Tuberculosis like lesions (TBL) remains as one of the main causes of condemnation in swine reared in outdoor systems, producing significant economic losses [7, 17]. In a retrospective study carried out in southern Spain (2011 to 2016) 85\% of totally condemned pig carcasses were related to generalised TBL [19]. According to the heterogeneity in pathology, microbiology and immunological features of TBL, the present study was designed to determine the organic distribution of MTC, T. pyogenes and streptococci as the main etiologic agents involved in TBL in free-range pigs as well as to characterise histological lesions of generalised TBL and the molecular diversity of $T$. pyogenes and streptococci species.

Microscopically, TBL are characterised as pyogranulomas and granulomas at different evolutionary stages (stages I to IV) in lymph nodes and other organic locations. Although different studies suggest that TBL are frequently limited to head lymph nodes [23], different 
Table 2 PFGE analysis of selected microorganisms isolated from different organic localization from pigs with generalised TBL

\begin{tabular}{|c|c|c|c|c|c|c|c|c|c|c|}
\hline \multirow[t]{2}{*}{ Microorganism } & \multirow{2}{*}{$\begin{array}{l}\text { Animal } \\
\text { ID }\end{array}$} & \multicolumn{8}{|c|}{ PFGE patterns identified } & \multirow[t]{2}{*}{ Farm } \\
\hline & & $\mathrm{SLN}^{\mathrm{a}}$ & PLN & SILN & GHLN & Lungs & Liver & Spleen & Tonsils & \\
\hline \multirow[t]{8}{*}{ T. pyogenes } & \#6 & $-^{*}$ & - & - &.$^{*}$ & A & $A^{*}$ & - & - & 5 \\
\hline & $\# 8$ & $A^{*}$ & A & A & A & A & A & - & - & 6 \\
\hline & $\# 11$ & $\stackrel{-}{*}^{*}$ & - & A &.$^{*}$ & - & $A^{*}$ & A & - & 7 \\
\hline & \#19 & $-^{*}$ & $-^{*}$ & B & - & - & B & $-^{*}$ & B & 7 \\
\hline & $\# 20$ &.$^{*}$ & C & B & $-^{*}$ & B & B & - & - & 7 \\
\hline & $\# 21$ & $C^{*}$ & $-^{*}$ & $\mathrm{D}$ & - & C & $C^{*}$ & - & C & 12 \\
\hline & $\# 22$ & $\mathrm{D} 1^{*}$ & D & B1 & B1 & B & B1 & B & - & 12 \\
\hline & $\# 23$ & - & $\mathrm{B}^{*}$ & $\mathrm{~B}^{*}$ & $-^{*}$ & $-^{*}$ &.$^{*}$ & $-^{*}$ & $\check{-}^{*}$ & 12 \\
\hline \multirow[t]{5}{*}{ S. porcinus } & $\# 10^{*}$ & G & - & $\mathrm{H}$ & - & - & - & । & - & 7 \\
\hline & $\# 19^{*}$ & - & - & C & - & - & $A$ & - & C & 12 \\
\hline & $\# 23^{*}$ & - & - & - & - & B & - & - & C & 12 \\
\hline & $\# 26^{*}$ & E & - & - & $\mathrm{F}$ & $E$ & $\mathrm{~F}$ & $\mathrm{~F}$ & E & 14 \\
\hline & \#34 & - & - & D & D & D & - & - & D & 11 \\
\hline \multirow[t]{6}{*}{ S. dysgalactiae spp. equisimilis } & $\# 7^{*}$ & - & - & B & A & A & - & - & - & 6 \\
\hline & $\# 9^{*}$ & $C$ & - & - & $D$ & $C$ & $C$ & - & - & 7 \\
\hline & $\# 29^{*}$ & - & - & - & - & $F$ & $F$ & - & - & 15 \\
\hline & \#33 & - & - & $\mathrm{G}$ & - & $\mathrm{F}$ & - & - & G1 & 15 \\
\hline & $\# 35^{*}$ & - & - & - & - & $\mathrm{F}$ & $\mathrm{F}$ & $E$ & - & 16 \\
\hline & $\# 37^{*}$ & - & - & $\mathrm{H}$ & $\mathrm{H}$ & - & - & - & - & 4 \\
\hline
\end{tabular}

${ }^{a}$ SLN, PLN, SILN and GHLN: submandibular, popliteal, superficial inguinal and gastrohepatic lymph nodes, respectively Different letters (A, B-B1, C, D-D1) correspond with different PFGE patterns

-: negative

*MTC detected from this sample by qPCR analysis

Cases with the same PFGE pattern isolated from two or more organs are marked in bold

body locations such as other lymph nodes or thoracic or abdominal organs can be also affected in pigs [15]. In our study, microscopic lesions were mainly observed in SLN and GHLN, with only occasional involvement of SILN and PLN, and in a lesser extent in internal organs, such as lungs, liver and spleen. The fact that stage III and stage IV granulomas were detected both in SLN and GHLN support the hypothesis that both the respiratory and digestive routes of infection play an important role in pigs, as previously suggested [23, 26]. Early stage granulomas (stage I and stage II) were mainly observed in lungs, liver and spleen, which suggests that the infection in these organs was more recent and probably associated to the dissemination from a primary focus which might be potentially present in SLN or GHLN.

Granulomas with different evolutionary stages were observed within the same organ. These findings can be explained because tuberculous lesions may change over time coinciding with periods of exacerbation or remission of the disease [18] and may be related to the balance of the local immune response within each granuloma, with slight differences in inflammatory pathways contributing to diverse granuloma architectures and functions, which may have different consequences for bacterial control [22]. Our results highlight the importance of evaluating histological characteristics of granulomas to better understand the pathogenesis of the disease as well as in the monitoring of control measures.

MTC was detected in 31 (83.78\%) out of 37 animals and $90(90 / 262)$ samples. These results were expected according to the convenient selection of farms with previous history of TBL and raised under outdoor systems, sharing resources with other domestic and wild species, such as bovine and caprine species, wild boar and wild ruminants, that play a role in the direct or indirect transmission of the disease to this species [26]. In the six $\mathrm{MTC}^{-}$animals detected in our study stage IV granulomas were the most common ones in the lymph nodes; however, stage I and stage II granulomas were also observed. The negative results obtained in our study may be, at least in part, justified by the difficult detection of MTC DNA from deeply necrotic and mineralised lesions or by splitting up the lesions to be included in the histopathological study as well as in qPCR analysis during the sampling.

In $\mathrm{MTC}^{+}$animals, mycobacteria were detected most frequently in SLN (24/31; 77.42\%) and GHLN (19/31; $61.29 \%)$. It has been suggested that the digestive tract is 
an important route of transmission of tuberculosis in pigs due to the consumption of contaminated feed, which could explain the high frequency of detection in this organic location $[1,10]$. It is interesting to highlight that examination of both SLN and GHLN allowed the detection of $93.55 \%$ of the $\mathrm{MTC}^{+}$animals. Therefore, both lymph nodes should be included in the sampling in epidemiological surveillance programs to improve the sensibility in the identification of positive animals. Furthermore, MTC was also detected in other organs, such as spleen (9/31), liver (8/31), lungs (8/31) and tonsils (4/ 31 ), as evidenced in wild boar $[3,23]$, with the potential risk of excretion by numerous routes (nasal secretions, oral, faeces) and transmission to other animals by direct or indirect contact as well as to the environment. Further studies are encouraged to determine the epidemiological role of this species in the maintenance of the disease in outdoor systems.

In addition to MTC, we found a broad range of microorganisms in different organic locations, with Trueperella pyogenes, $S$. dysgalactiae spp. equisimilis and $S$. porcinus as the main non-tuberculous pathogens detected, alone or in combination with MTC. A wide distribution of these microorganisms in different body compartments was also observed; $T$. pyogenes was frequently isolated from TBL in the liver (23.53\%) and lymph nodes (18.92\% SLN and $19.44 \%$ SILN, respectively); $S$. porcinus was detected mainly in tonsils (42.86\%), lungs (13.51\%) and SLN (10.81\%); and S. dysgalactiae spp. equisimilis in SLN (13.51\%) and lungs (13.51\%). These species have already been associated with a high rate of whole carcass condemnation due to generalised lymphadenitis in free-range pigs [7, 25], emphasizing the importance of implementing control strategies against these microorganisms to reduce the impact of carcass condemnation at the slaughterhouse.

Both T. pyogenes and Streptococcus spp. are considered ubiquitous and opportunistic pathogens that cause different clinical conditions in pigs. Pigs are usually healthy carriers of these microorganisms in the skin, tonsils or respiratory, genitourinary and gastrointestinal tracts, but in addition these microorganisms can also be found in the environment, which favours continuous infections and reinfections of the animals [14]. Therefore, we decided to determine the genetic similarity of the isolates obtained at different organic locations from each animal using PFGE techniques [31]. In our study, T. pyogenes characterisation was performed using 6 different restriction enzymes and different incubation times, including SfiI, SmaI, Bsp120I, XbaI, XhoI and BcuI (data not shown). According to our preliminary study, the proposed PFGE protocol, based on restriction with $B c u \mathrm{I}$ $\left(10 \mathrm{IU}, 4 \mathrm{~h}\right.$ at $\left.37^{\circ} \mathrm{C}\right)$, is an adequate method for the genetic characterisation of $T$. pyogenes, which allowed obtaining a pattern of 15 to 18 bands well differentiated in the gel.

Four different PFGE patterns (A, B-B1, C, D-D1) at an $85 \%$ of genetic similarity were obtained from $T$. pyogenes isolates (GD 0.13). These results show the important role of this microorganism as etiological agent of porcine lymphadenitis and open the door to further studies to elucidate the pathogenesis and control measures of interest, such as vaccine-based strategies, against this disease.

However, a wide diversity of PFGE patterns were observed for Streptococcus species, S. porcinus isolates, with nine different PFGE patterns (GD 0.5), and S. dysgalactiae spp. equisimilis isolates, with eight different PFGE patterns (GD 0.47). These results are in agreement with previous studies of genetic diversity of streptococci from animals including $S$. porcinus [11], S. dysgalactiae spp. equisimilis [9] and S. suis [20,27] and evidence that TBL can be produced by different isolates, which should be taken into account when applying control measures against the disease, based on management and biosecurity measurement.

This information will allow gaining knowledge of interest to decipher the pathogenesis of TBL in pigs as well as identifying target organs for the diagnosis of the main pathogens involved in this process to avoid misdiagnosis and the implementation of holistic control measures.

\section{Conclusions}

Results of this study show that the SLN and GHLN are the most frequently organs affected from MTC, and they can be selected for the diagnosis in the surveillance programs of tuberculosis in pigs. Furthermore, other pathogens, such as $T$. pyogenes and streptococci, can be involved in disseminated infections, with and without mycobacterial involvement. The high genetic similarity observed in $T$. pyogenes isolates obtained from generalised TBL in this study, point to this pathogen as a key microorganism in porcine lymphadenitis and requires the adoption of specific control strategies. On the other hand, different isolates of Streptococcus spp. were detected due to opportunistic character of this species. Our results highlight the importance of establishing an adequate diagnosis to adopt the most appropriate control measures, such as those based on vaccination and biosecurity strategies.

\section{Material and methods}

\section{Experimental design and sampling}

A total of 37 free-range pigs with whole carcass condemnation due to generalised TBL according to the European Regulation for meat inspection (Regulation 2004/854/EC Regulation (EC) No 854/2004 of the 
European Parliament and of the Council of 29 April 2004 laying down specific rules for the organisation of official controls on products of animal origin intended for human consumption. OJ L 139, 30.4.2004, p. 206320) were selected and sampled at slaughterhouse. All animals were apparently healthy free-range pigs over 14-month-old raised in extensive systems from 16 farms located in southern Spain. To choose these animals, farms were conveniently selected according to two criteria: (1) farms with a previous history of condemnation due to TBL during the last 5 years and (2) farms with fattening pigs which can be followed at the slaughterhouse where the sampling was accomplished. Pigs from the selected farms slaughtered in two consecutive campaigns were evaluated by official meat inspectors and all condemned animals due to generalised TBL were sampled and included in the study. A minimum of one and a maximum of six pigs per farm were sampled and after routine meat inspection procedures, a total of 262 samples from 37 animals were obtained and distributed as follow: submandibular (SLN, 37), superficial inguinal (SILN, 37), gastrohepatic (GHLN, 36), and popliteal (PLN, 36) lymph nodes, lungs (37), liver (34), spleen (24) and tonsils (21). Lung, liver and spleen samples were only collected when compatible gross lesions were observed. Scattered samples from the same animal were not occasionally available due to sampling by the official veterinary services for routine diagnosis. To avoid cross contamination, different sets of sterile instruments and vials were used to collect and transport samples from each animal.

Whenever possible, one well-defined lesion was selected from each organ and was divided into two portions: one portion was subjected to histopathological analysis and the other one was immediately submitted to bacteriology and frozen at $-20^{\circ} \mathrm{C}$ to perform qPCR assays. However, when small-sized disseminated (miliar) lesions were observed, similar in gross appearance and close lesions were selected and submitted to each analysis. Different sets of sterile instruments and vials were used to avoid cross contamination.

\section{Histopathological analysis}

Tissue samples were fixed in $10 \%$ neutral buffered formaldehyde, routinely processed, and embedded in paraffin blocks. Four $\mu \mathrm{m}$ sections were stained with haematoxylin and eosin and examined by light microscopy. Each sample was classified according to the identification of specific structures as described by Cardoso-Toset et al. [7]. Thus, granulomas were classified into four stages (I-IV) based on the pathological characterisation of TB granulomas [7, 32].

\section{TB diagnosis}

Presence of $M T C$ and $M A C$ was tested by an in-house duplex qPCR [6]. Briefly, fat and connective tissue were removed from samples and up to $2 \mathrm{~g}$ of tissue were homogenised in a stomacher with $10 \mathrm{ml}$ of sterile distilled water for $2 \mathrm{~min}$. The obtained solution was centrifuged for $10 \mathrm{~min}$ at $1400 \mathrm{~g}$ resulting in a pellet for each sample. Genomic DNA was extracted from $25 \mathrm{mg}$ of tissue homogenate using NucleoSpin ${ }^{\circ}$ Tissue DNA isolation kit (Macherey-Nagel GmbH, Düren, Germany) according to the manufacturer's instructions.

qPCR reactions were run in duplicate in a Agilent Technologies Mx3000P thermocycler under the following conditions: initial denaturation at $95{ }^{\circ} \mathrm{C}$ for $10 \mathrm{~min}$, 40 cycles of amplification consisting of denaturation at $95^{\circ} \mathrm{C}$ for $30 \mathrm{~s}$, primer annealing at $65^{\circ} \mathrm{C}$ for $30 \mathrm{~s}$, and extension at $72{ }^{\circ} \mathrm{C}$ for $30 \mathrm{~s}$. DNA from $M$. bovis and $M$. avium isolates and non-template controls were included in each assay and used as positive and negative controls, respectively.

\section{Bacterial isolation}

Samples were plated on Blood Agar Base and Columbia Blood Agar Base with nalidixic acid and colistin sulfate (Oxoid ltd., Hampshire, UK), supplemented with 5\% sterile defibrinated sheep blood and incubated both in aerobic and microaerophilic $\left(5 \% \mathrm{CO}_{2}\right)$ conditions at $37^{\circ} \mathrm{C}$ for $48 \mathrm{~h}$. Colonies were selected and identified as previously described [7]. Further biochemical identification was performed using commercial identification galleries ( $\mathrm{API}^{\circ} \mathrm{C}$ Coryne and $\mathrm{API}^{\circ}$ 20Strep, bioMérieux, Marcy-l'Etoile, France) according to manufacturer's instructions. Isolates were identified as a species only if identification scores in the multi-substrate identification systems were excellent, very good or good (90.0-99.9\% ID); otherwise, identification was made only at the genus level (spp.). Latex agglutination test (Streptococcal grouping kit, Oxoid ltd, Hampshire, UK) and Christie Atkins Munch-Petersen test (CAMP test) were used for identification according to previous reports [30]. Pure cultures of each isolate were stored at $-70^{\circ} \mathrm{C}$.

\section{Pulsed-field gel electrophoresis (PFGE) analysis}

The genetic similitude of $T$. pyogenes isolates was determined by genomic DNA digestion with $B c u$ I. Briefly, $T$. pyogenes isolates were grown on Blood agar with $5 \%$ defibrinated sheep blood (Oxoid ltd) an incubated under microaerophilic $\left(5 \% \mathrm{CO}_{2}\right)$ conditions at $37^{\circ} \mathrm{C}$ for $24-48$ $\mathrm{h}$. Isolates were harvested for preparing agarose plugs as described previously by Vela et al. [31]. DNA plugs were equilibrated in restriction buffer for $30 \mathrm{~min}$ at $37^{\circ} \mathrm{C}$ followed by digestion for $4 \mathrm{~h}$ at $37^{\circ} \mathrm{C}$ in $150 \mu \mathrm{l}$ of reaction mixture containing $10 \mathrm{U} \mathrm{BcuI}$ (Thermo Fischer Scientific Inc., USA). Macrorestriction fragments were 
separated on a $1 \%$ agarose gel at $14{ }^{\circ} \mathrm{C}$ with $0.5 \mathrm{X}$ TBE (Tris-Borate-EDTA) buffer. Electrophoresis was done using a constant voltage of $6 \mathrm{~V} / \mathrm{cm}$ for $24 \mathrm{~h}$ on a CHEF DR-III electrophoresis system (Bio-Rad Laboratories; Hercules, CA, USA). The pulse time was ramped from 0.1 to $10 \mathrm{~s}$ and Salmonella serotype Branderup strain H9812 was digested with $\mathrm{XbaI}$ and included for DNA fragment size determination [13].

The genetic typing of Streptococcus isolates was done by PFGE after genomic DNA digestion with Bsp120I and SmaI following the protocol described by Vela et al. [19]. All the PFGE patterns (PFPs) obtained in this study were visually examined and classified as different PFPs according to criteria of Tenover et al. [28].

\section{Abbreviations \\ DNA: Deoxyribonucleic acid; GD: Genetic diversity; GHLN: Gastrohepatic lymph node; M. bovis: Mycobacterium bovis; M. avium: Mycobacterium avium; MAC: Mycobacterium avium complex; MTC: Mycobacterium tuberculosis complex; PFGE: Pulsed-field gel electrophoresis; PFPs: PFGE patterns; PLN: Popliteal lymph node; qPCR: Quantitative polymerase chain reaction; SILN: Superficial inguinal lymph node; SLN: Submandibular lymph node; S. dysgalactiae spp. equisimilis: Streptococcus dysgalactiae subspecies equisimilis; S. porcinus: Streptococcus porcinus; TBL: Tuberculosis like lesions; T. pyogenes: Trueperella pyogenes}

\section{Authors' contributions}

Study conception and design: ILM, JGL, CTI, LCO. Data acquisition: FCT, AGR, IMRG, LGG. Data analysis and interpretation: ILM, JGL, AIV, FCT, LCO, CTI. Drafting the manuscript: FCT, LGC, IMRG, JGL, ILM. All authors read, critically revised and approved the final manuscript.

\section{Funding}

This study was financially supported by the Centre for the Development of Industrial Technology (CDTI) of Spain (project reference IDI-20111632/ 20111633). Cardoso-Toset F. was funded by a grant of the Agrifood Campus of International Excellence Programme (ceiA3) from the Ministry of Education, Culture and Sport and by the Santander Universities Global Division. Gómez-Laguna J. is supported by a "Ramón y Cajal" contract of the Spanish Ministry of Economy and Competitiveness (RYC-2014-16735).

\section{Availability of data and materials}

All datasets used in this study are available from the corresponding author on reasonable request.

\section{Consent for publication}

All authors gave their consent for publication.

\section{Competing interests}

The authors declare that they have no competing interests.

\section{Author details}

'CICAP - Food Research Centre, Pozoblanco, 14400 Córdoba, Spain. 2Department of Anatomy and Comparative Pathology, University of Córdoba, International Excellence Agrifood Campus 'CeiA3', 14071 Córdoba, Spain. ${ }^{3}$ Department of Animal Health, University of Córdoba, International Excellence Agrifood Campus 'CeiA3', 14071 Córdoba, Spain. ${ }^{4}$ Department of Animal Health, Faculty of Veterinary Medicine, Complutense University, Madrid, Spain. ${ }^{5}$ VISAVET Health Surveillance Centre, Faculty of Veterinary Medicine, Complutense University, Madrid, Spain.

Received: 21 July 2020 Accepted: 13 October 2020

Published online: 04 December 2020

\section{References}

1. Arega SM, Conraths FJ, Ameni G. Prevalence of tuberculosis in pigs slaughtered at two abattoirs in Ethiopia and molecular characterization of
Mycobacterium tuberculosis isolated from tuberculous-like lesions in pigs. BMC Vet Res. 2013;9:97 https://doi.org/10.1186/1746-6148-9-97.

2. Bailey SS, Crawshaw TR, Smith NH, Palgrave CJ. Mycobacterium bovis infection in domestic pigs in Great Britain. Vet J. 2013;198:391-7 https://doi. org/10.1016/j.tvjl.2013.08.035

3. Barasona JA, Vicente J, Diez-Delgado I, Aznar J, Gortazar C, Torres MJ. Enviromental presence of Mycobacterium tuberculosis complex in aggregation points at the wildlife/livestock interface. Transbound Emerg Dis. 2017;64:1148-58 https://doi.org/10.1111/tbed.12480

4. Bollo E, Ferroglio E, Dini V, Mignone W, Biolatti B, Rossi L. Detection of Mycobacterium tuberculosis complex in lymph nodes of wild boar (Sus scrofa) by a target-amplified test system. J Vet Med B Infect Dis Vet Public Health. 2000;47:337-42 https://doi.org/10.1046/j.1439-0450.2000.00354.x.

5. Cadena AM, Fortune SM, Flynn JL. Heterogeneity in tuberculosis. Nat Rev Immunol. 2017;17:691-702 https://doi.org/10.1038/nri.2017.69.

6. Cardoso-Toset F, Luque I, Amarilla SP, Gómez-Gascón L, Fernández L, Huerta $B$, et al. Evaluation of rapid methods for diagnosis of tuberculosis in slaughtered free-range pigs. Vet J. 2015;204:232-4 https://doi.org/10.1016/j. tvjl.2015.01.022.

7. Cardoso-Toset F, Gómez-Laguna J, Amarilla SP, Vela Al, Carrasco L, Fernández-Garayzábal JF, et al. Multi-etiological nature of tuberculosis-like lesions in condemned pigs at the slaughterhouse. PLoS One. 2015;10: e0139130 https://doi.org/10.1371/journal.pone.0139130.

8. Contzen M, Sting R, Blazey B, Rau J. Conynebacterium ulcerans from diseased wild boars. Zoonoses Public Health. 2011;58:479-88 https://doi.org/10.1111/ j.1863-2378.2011.01396.x.

9. Costa P, Ferreira AS, Amaro A, Albuquerque T, Botelho A, Couto A, et al. Enhanced detection of tuberculous mycobacteria in animal tissues using a semi-nested probe-based real-time PCR. PLoS One. 2013;8:e813372013 https://doi.org/10.1371/journal.pone.0081337.

10. Di Marco V, Mazzone P, Capucchio MT, Boniotti MB, Aronica V, Russo M, et al. Epidemiological significance of the domestic black pig (Sus scrofa) in maintenance of bovine tuberculosis in Sicily. J Clin Microbiol. 2012;50:120918 https://doi.org/10.1128/JCM.06544-11.

11. Duarte RS, Barros RR, Facklam RR, Teixeira LM. Phenotypic and characteristics of Streptococcus porcinus isolated from human sources. J Clin Microbiol. 2005;43: 4592-601. https://doi.org/10.1128/JCM.43.9.4592-4601.2005.

12. García-Jiménez WL, Salguero FJ, Fernández-Llario P, Martínez R, Risco D, Gough J, et al. Immunopathology of granulomas produced by Mycobacterium bovis in naturally infected wild boar. Vet Immunol Immunop. 2013;156:54-63 https://doi.org/10.1016/j.vetimm.2013.09.008.

13. Hunter SB, Vauterin P, Lambert-Fair MA, Van Duyne MS, Kubota K, Graves L, et al. Establishment of a universal size standard strain for use with the PulseNet standardized pulsed-field gel electrophoresis protocols: converting the national databases to the new size standard. I Clin Microbiol. 2005;43: 1045-50 https://doi.org/10.1128/JCM.43.3.1045-1050.2005.

14. Jarosz LS, Gradzki Z, Kalinowski M. Trueperella pyogenes infections in swine: clinical course and pathology. Pol J VetSci. 2014;17:395-404 https://doi.org/ 10.2478/pjvs-2014-0055.

15. Johansen TB, Agdestein A, Lium B, Jorgensen A, Djonne B. Mycobacterium avium subsp. hominisuis infection in swine associated with peat used for bedding. Biomed Rest. 2014;Article ID 189649:8 https://doi.org/10.1155/ 2014/189649.

16. Komijn RE, Wisselink HJ, Rijsman VMC, Stockhofe-Zurwieden N, Bakker D, van Zijderveld FG. Granulomatous lesions in lymph nodes of slaughter pigs bacteriologically negative for Mycobacterium avium subsp. avium and positive for Rhodococcus equi. Vet Microbiol. 2007;120:352-7 https://doi.org/ 10.1016/j.vetmic.2006.10.031

17. Lara GH, Ribeiro MG, Leite $C Q$, Paes $A C$, Guazzelli A, da Silva AV, et al. Occurrence of Mycobacterium spp. and other pathogens in lymph nodes of slaughtered swine and wild boars (Sus scrofa). Res Vet Sci. 2011;90:185-8 https://doi.org/10.1016/j.rvsc.2010.06.009.

18. Lenaerts A, Barry CE, Dartois V. Heterogeneity in tuberculosis pathology, microenviroments and therapeutic responses. Immunol Rev. 2015;264:288307 https://doi.org/10.1111/imr.12252.

19. Linares R, Cardoso-Toset F, Gómez-Laguna J, Carrasco L, Gómez-Gascón L, Amarilla SP, et al. Retrospective study of condemnation associated with lymphadenitis in pigs reared in free-range systems. In: Berkshire D, Strugnell B, Done S, Walker J, editors. Proceedings of the Joint Meeting of the $5^{\text {th }}$ ESPHM and 50th Anniversary PVS of Great Britain. Edinburgh: United Kingdom; 2013. pp 136. 
20. Luque I, Blume V, Borge C, Vela Al, Perea JA, Márquez JM, et al. Genetic analysis of Streptococcus suis isolates recovered from diseased and healthy carrier pig at different stages of production on a pig farm. Vet J. 2010;186: 396-8 https://doi.org/10.1016/j.tvil.2009.09.005.

21. Makrai L, Kobayashi A, Matsuoka M, Sasaki Y, Kakuda T, Dénes B, et al. Isolation and characterisation of Rhodococcus equi from submaxillary lymph nodes of wild boars (Sus scrofa). Vet Microbiol. 2008;15:318-23 https://doi. org/10.1016/j.vetmic.2008.04.009.

22. Marakalala MJ, Martinez FO, Plüddermann A, Gordon S. Macrophage heterogeneity in the immunopathogenesis of tuberculosis. Front Microbiol. 2018;9:1028 https://doi.org/10.3389/fmicb.2018.01028

23. Martín-Hernando MP, Höfle U, Vicente J, Ruiz-Fons F, Vidal D, Barral M, et al. Lesions associated with Mycobacterium tuberculosis complex infection in the European wild boar. Tuberculosis. 2007;87:360-7 https://doi.org/10.1016/j. tube.2007.02.003.

24. Miranda C, Matos M, Pires I, Correia-Neves M, Ribeiro P, Alvares S, VieiraPinto $M$, et al. Diagnosis of Mycobacterium avium complex in granulomatous lymphadenitis in slaughtered domestic pigs. J Comp Pathol. 2012;147:401-5 https://doi.org/10.1016/j.jcpa.2012.05.005.

25. Oliveira M, Barroco C, Mottola C, Santos R, Lemsaddek A, Tavares L, et al. First report of Corynebacterium pseudotuberculosis from caseous lymphadenitis lesions in black Alentejano pig (Sus scrofa domesticus). BMC Vet Res. 2014;218:1-5 https://doi.org/10.1186/s12917-014-0218-3.

26. Parra A, Fernández-Llario P, Tato A, Larrasa J, García A, Alonso JM, et al. Epidemiology of Mycobacterium bovis infection of pigs and wild boars using a molecular approach. Vet Microbiol. 2003;97:122-33 https://doi.org/10. 1016/j.vetmic.2003.08.007.

27. Sanchez del Rey V, Fernandez-Garayzabal JF, Mentaberre G, Briones V, Lavin $\mathrm{S}$, Dominguez $\mathrm{L}$, et al. Characterisation of Streptococcus suis isolates from wild boars (Sus scrofa). Vet J. 2014;200:464-7 https://doi.org/10.1016/j.tvjl. 2014.03.013

28. Tenover FC, Arbeit RD, Goering RV, Mickelsen PA, Murray BE, Persing DH, et al. Interpreting chromosomal DNA restriction patterns produced by pulsed-field gel electrophoresis: criteria for bacterial strain typing. I Clin Microbiol. 1995;33:2233-9 PMID: 7494007.

29. Thomas-Bachli AL, Pearl DL, Friendship RM, Berke O. Exploring relationships between whole carcass condemnation abattoir data, non-disease factors and disease outbreaks in swine herds in Ontario (2001-2007). BMC Res Notes. 2014;7:185 https://doi.org/10.1186/1756-0500-7-185.

30. Ülbegi-Mohyla H, Hijazin M, Alber J, Lämmler C, Hassan AA, Abdulmawjood A, et al. Identification of Arcanobacterium pyogenes isolated by post mortem examinations of a bearded dragon and a gecko by phenotypic and genotypic properties. J Vet Sci. 2010;11:265-7 https://doi.org/10.4142/jvs. 2010.11.3.265.

31. Vela Al, Goyche J, Tarradas C, Luque I, Mateos A, Moreno MA, et al. Analysis of genetic diversity of Streptococcus suis clinical isolates from pigs in Spain by pulsed-field gel electrophoresis. J Clin Microbiol. 2003;41:2498-502 https://doi.org/10.1128/JCM.41.6.2498-2502.2003.

32. Wangoo A, Johnson L, Gough J, Ackbar R, Inglut S, Hicks D, et al. Advanced granulomatous lesions in Mycobacterium bovis-infected cattle are associated with increased expression of type I procollagen, gammadelta (WC1+) T cells and CD 68+ cells. J Comp Pathol. 2005;133:223-34 https://doi.org/10.1016/j. jсра.2005.05.001.

\section{Publisher's Note}

Springer Nature remains neutral with regard to jurisdictional claims in published maps and institutional affiliations.

Ready to submit your research? Choose BMC and benefit from:
- fast, convenient online submission
- thorough peer review by experienced researchers in your field
- rapid publication on acceptance
- support for research data, including large and complex data types
- gold Open Access which fosters wider collaboration and increased citations
- maximum visibility for your research: over 100M website views per year
At BMC, research is always in progress.
Learn more biomedcentral.com/submissions

